\title{
PLUTARCO Y FLAVIO JOSEFO \\ EN LA OBRA DEL JESUITA MATÍAS SÁNCHEZ: EL CONCEPTO CLÁSICO DE LA HISTORIA
}

\author{
Francisco Salas Salgado \\ Universidad de la Laguna \\ frasalas@ull.edu.es
}

\begin{abstract}
RESUMEN
El presente artículo es una primera aproximación a una obra del siglo XVIII de contenido histórico desde el punto de vista clásico. Se trata de un manuscrito, afortunadamente editado, que describe los avatares de la Compañía de Jesús en Canarias, escrito por el jesuita granadino Matías Sánchez. Esta obra contiene muchas citas en latín y referencias diversas a personajes de la Antigüedad Clásica. Pero también en su prólogo aparecen los criterios que sigue este jesuita en la redacción de su obra, donde se vincula a Plutarco y especialmente a Flavio Josefo.
\end{abstract}

Palabras Clave: Tradición Clásica, concepto de Historia, Plutarco, Flavio Josefo.

PLUTARCH AND FLAVIUS JOSEPHUS IN THE JESUIT MATÍAS SÁNCHEZ'S WORK:

THE CLASSICAL CONCEPT OF HISTORY

\begin{abstract}
This paper attempts to approach a historical work of $18^{\text {th }}$ century from the classical perspective. This is a manuscript, fortunately edited, that describes the vicissitudes of the Jesus Company in the Canary Islands, written by the jesuit born in Granada, Matías Sánchez. This work contains many Latin quotations and various references to characters from Classical Antiquity. But also in his prologue appear the criteria followed by this jesuit in the composition of his work, where he is linked to Plutarch and especially to Josephus.
\end{abstract}

KeYwords: Classic Survival, Concept of History, Plutarch, Flavius Josephus.

La publicación por parte del Instituto de Estudios Canarios de la obra titulada Semi-historia de las Fundaciones, Residencias, o Colegios que tiene la Compañia de Jesus en las Islas Canarias, del jesuita granadino Matías Sánchez ha permitido rescatar un texto relevante para conocer el devenir que tuvo esta orden religiosa en Canarias. Pero aparte de su valor historiográfico, esta obra tiene otras cualidades, entre ellas, por lo que aquí se trata, la existencia de muchos elementos que están relacionados con el Mundo Clásico, los cuales sirven de ejemplo de la continuidad que ha tenido la cultura grecolatina en todos los momentos de la historia y en obras de temática y contenido diversos. 
Sobre esta cuestión había llamado la atención M. Martínez (2007: 307-309) en un lúcido trabajo que, a pesar de estar centrado en el siglo XIX, tiene validez general. Allí reclamaba una nueva lectura y estudio de las obras relacionadas con la historiografía canaria en las que pudieran existir elementos que estuvieran vinculados de forma evidente con el mundo clásico, tanto en historiadores patrios como extranjeros.

Esta pervivencia clásica en la Semi-Historia de Matías Sánchez, anunciada desde el propio título ${ }^{1}$, aparece desde el comienzo cuando trata en no pocas páginas del origen de las islas y su pasado mitológico ${ }^{2}$ o se refiere también a determinados mitos. Aparte de esto abundan las citas latinas y la mención a personajes de la Antigüedad Clásica.

Sin embargo, para esta ocasión ${ }^{3}$, voy a centrar la atención en un tema más específico, de menor bulto pero creo que igualmente interesante. Trataré de mostrar el concepto que este jesuita tiene de la historia y relacionarlo con los modelos antiguos que siguió, todo lo cual se esboza en el pequeño «Prologo» del comienzo. Pero antes de esto conviene decir algo de este autor y de esta obra ${ }^{4}$.

${ }^{1}$ El título en extenso es: Semi-Historia De las Fundaciones, Residencias, o Colegios que tiene la Compañia de Jesus en las Islas Canarias: Origen, Progresos y estado presente de ellas: Con una breve descripcion de aquellas siete Islas, un Resumen de su Conquista. Algunos problemas concernientes a ellas, Singularmente a la famosa Encantada, o de San Borondon. La transcripción de esta obra, editada en el año 2008, va acompañada de un estudio introductorio y notas debidas al historiador F. Fajardo Spínola. Está dividida en diferentes partes que a su vez tienen diferentes secciones:1) Portada; 2) Indice; 3) [Poesías preliminares]; 4) «Prologo»; 5) «Advertencia»; 6) «Introduccion a la Semi-historia: descripción Geografica, etc.» (consta de 9 capítulos); 7) «Parte $1^{\text {a }}$. Ocasión y principios remotos de aq ${ }^{\text {as }}$ Residencias» (consta de tres secciones); 8) «Parte 2a. Progresos de las tres Fundaciones» (consta de tres secciones); y 9) "Apéndice. Resumen de los sucesos hasta el año 40 inclusive». Advierto que en las citas que se hacen de esta obra sigo esta edición, en la que se ha mantenido íntegramente la grafía del manuscrito, siguiendo las recomendaciones de la "Comisión de Estudio Histórico del Español de América» para documentos de Andalucía y Canarias.

${ }^{2}$ Sin embargo, cabe indicar que en este aspecto es deudor de la obra de Cristóbal Pérez del Cristo, Excelencias y Antigüedades de las siete Islas Canarias, 1679. Dos ejemplares de esta obra se encontraban en el Colegio de La Orotava (Rodríguez Bravo, 2015: 232).

${ }^{3}$ Con todo mi aprecio dedico este breve trabajo al Dr. D. Ángel Martínez Fernández, catedrático de Filología griega de la Universidad de La Laguna, grandísimo investigador y profesor mío en mis años dicentes, a quien homenajea merecidamente este número de Fortunatae, revista de la que fue su primer director. Quisiera que estas páginas, cortas pero llenas de agradecimiento, sean muestra de mi admiración y respeto por su grandísima labor académica. Es curioso -y no me resisto a decirlo aquí- que, revisando hace poco los papeles y cuadernos de esos lejanos años de la Licenciatura, una de las asignaturas que me impartiera nuestro querido profesor y amigo fuera la «Lengua griega III", correspondiente al primer cuatrimestre del tercer curso. En ella nos dedicamos a la lectura y traducción de los Libros I y VII de Tucídides y, en la explicación del texto griego del comienzo de la Historia de la guerra del Peloponeso, empezamos a ver las semejanzas y diferencias conceptuales de este autor comparándolas con Heródoto y Jenofonte. El destino o la casualidad han querido que los nombres de algunos de estos grandes historiadores griegos vuelvan a aparecer en el texto que aquí se estudia.

${ }^{4}$ Sigo evidentemente los datos que se aportan en Sánchez, 2008: 9-66. 
Matías Pedro Sánchez Bernalt nació en Granada (Santa Fe) en 1697. Su ingreso en la Compañía de Jesús fue en 1711. En sus estudios, que llevó a cabo en la casa de formación de la Compañía en Granada, adquirió un sólido conocimiento en la lengua latina y en las disciplinas teológicas, algo lógico si tenemos en cuenta las exigencias del programa de estudios de la Compañía, la conocida Ratio Studiorum. Ejerció en la década de 1720 como profesor de Gramática y Teología en los colegios de Cádiz, Baeza y Utrera. Desestimada su solicitud de ir a las misiones de Uruguay y Filipinas, fue destinado finalmente a Canarias, donde llegó (concretamente a Tenerife) en septiembre de 1729 .

Fue nombrado Superior del Colegio de La Orotava, villa en la que permaneció hasta 1736, momento de su partida a la Península, con un breve intervalo de dos años, de 1732 a 1734, como operario en Las Palmas de Gran Canaria.

De nuevo en la Península estuvo en varios colegios andaluces hasta ser enviado a Badajoz (Higuera de la Real) donde permaneció los últimos diecisiete años de su vida, muriendo en el año 1762.

Su curiosidad científica le llevó a pertenecer a la Real Sociedad de Medicina de Sevilla, relacionarse con figuras del catolicismo ilustrado español y participar en diversas disputas intelectuales, algo muy del gusto de la época. Al parecer fue autor de otros escritos relacionados con la enseñanza, tema que le preocupaba especialmente ${ }^{5}$, e intervino activamente en la polémica que se suscitó tras la traducción del texto de Luis Antonio de Verney, alias «Barbadiño", El verdadero método de estudiar, donde se censuraban los métodos de enseñanza que se seguían en esos momentos, vinculados a la escolástica, y se atacaban obras realizadas por algunos padres de la Compañía ${ }^{6}$. También dejó escrita una historia del Colegio extremeño de Higuera del Real.

En lo que se refiere a la obra que aquí se trata, la Semi-Historia, fue empezada en las Islas y terminada en el colegio de Málaga. Llega esta crónica hasta el año 1740, cuatro años después de su partida, sirviéndose para ello de las noticias que le hacían llegar desde los colegios isleños.

No se sabe de la existencia de otra copia de esta obra, a pesar de que el autor quería que se hiciese una para que fuese enviada a Roma y otra a Canarias, a fin de que hicieran uso de la misma los colegios que la compañía tenía allí.

El manuscrito original se encuentra en la British Library ${ }^{7}$ sin que se sepa ciertamente cómo llegó. Se tiene constancia de que fue regalado a D. José Cevallos,

${ }^{5}$ Así: El crítico anticritico, o problemas varios concernientes a diversas facultades y ciencias, maiormente Historia, Phisica, Theologia y erudicion varia, según el gusto de la moderna literatura, 1756 y El padre de familias brevemente instruido en sus muchas obligaciones de padre, editado en Madrid en 1792.

${ }^{6}$ Sobre todo la Gramática del P. Álvarez, muy difundida en su época. Parece que Matías Sánchez se esconde detrás de la obra Reforma del reformador Barbadiño, escrita en 1761 en tres volúmenes manuscritos, con el pseudónimo Pedro Trebnal (su segundo nombre y el apellido materno modificado).

${ }^{7}$ Es un tomo en $8^{\circ}$ de 221 páginas escritas a doble cara, y numeradas solo por el anverso Apunta Fajardo (cf. Sánchez, 2008: 11) en nota algunos datos físicos de este manuscrito. En el lomo se lee: «Mus. Brit. I Jure Empt. I Plut. CXLVIII.B»; y en la primera hoja: «Purchd. of B. Quaritch, 
eminente intelectual sevillano de la época de la Ilustración, de lo que da cuenta una nota que se encuentra en los preliminares del ejemplar londinense:

$\mathrm{D}^{\mathrm{n}} \mathrm{Jph}$ Zevallos Canonigo de Sevilla, q acaba de morir, tenia un manuscrito de la Historia moderna de Canarias, que escrivio el Padre Mathias Sanchez, jesuita; y se necesita un empeño poderoso, y eficaz, para que, antes que otro lo tome, se compre en Sevilla, antes que se abra a almoneda ${ }^{8}$.

Se supone que esta anotación pudo realizarla don Miguel de Espinosa, Conde del Águila. Otra nota, también en este ejemplar, («De la librería del $S^{\mathrm{r}}$ Marquès de Loreto») lleva a considerar que pudo pertenecer a Nicolás de Campo, amigo personal de Cevallos?.

Una copia de la Semi-Historia se encuentra en la Real Sociedad de Amigos del País de Tenerife, donada por José Rodríguez Moure, en tres volúmenes, manuscrito que pudo tener en su momento José de Viera y Clavijo. Los dos primeros volúmenes tienen la misma letra, el tercero debió de escribirlo otra mano ${ }^{10}$. Esta copia tuvo que realizarse en la Península entre 1754 y 1776, y de la misma partió un tercer manuscrito realizado por José Feo y Ramos, que no se conserva. Fue Eloy Benito Ruano el que diera a conocer en 1855 que la copia de la biblioteca londinense era el original.

Avatares aparte, lo que es evidente es que la implicación de Sánchez en la vida y costumbres de los canarios, tanto entre los miembros de la nobleza como de las clases menos pudientes, va a tener mucho que ver con el contenido de la Semi-Historia. No se olvide, además, que se trata de la visión que ofrece un personaje foráneo de una realidad que en no pocas ocasiones le resultaba extraña, pero también admirable; de un viajero que no estuvo de paso en las islas sino que vivió largo tiempo en ellas y que contrastaba las costumbres de estas tierras con lo que pasaba en España.

Los temas que relaciona, junto al asunto principal que -recordemos- era el estado de los colegios de la Compañía de Jesús en Canarias, son muy diversos ${ }^{11}$.

13 may 1863». Se trata de una abreviatura que corresponde al librero británico de origen alemán Bernard Quaritch (1819-1899), que tuvo que tener este manuscrito antes de pasar a engrosar los fondos del Museo Británico.

${ }^{8}$ Sánchez, 2008: 14 .

${ }^{9}$ Concluye, sin embargo, Fajardo que la obra del jesuita granadino no aparece en el catálogo de la biblioteca del Conde del Águila, inventariada en 1786, dos años después de su muerte, y presupone «que la que creemos carta de Espinosa intentando comprar la Semi-Historia la añadió al cuerpo de ésta alguien que finalmente logró adquirirla, y que también se hizo con algunos de los papeles del conde, entre ellos la carta en cuestión, quizás ya en Londres» (Sánchez, 1988: 15).

${ }^{10}$ Aprecia Fajardo (cf. Sánchez, 2008: 16) que la letra es más moderna, se desarrollan las abreviaturas y se cuida la acentuación y el uso de las mayúsculas. En cambio aparecen errores, sobre todo en los textos en latín, y se omiten algunas líneas.

${ }^{11}$ Lo refiere ya en el propio «Prologo»: «El objeto pues de esta Relacion son las Residencias, o Colegios, que tiene y puede tener la Compa de Jhs en aquellas Islas: que algun tiempo juzgaron los superiores podrian formar mui en breve una Semiprovincia; $y$ ya parece estan arrependidos de aver pensado en ese tal qual principio» (Sánchez, 2008: 76). Habría que decir, para comprender mejor lo anterior, 
Se refiere así al origen mítico de las islas y a algunas leyendas canarias (el árbol santo de El Hierro, la isla de San Borondón), a la geografía (la posición de Canarias respecto a África y su naturaleza volcánica), al clima, la vegetación y la fauna, a la iglesia y la religión, al gobierno civil (Real Audiencia y corregidores) y militar y también a cuestiones de economía. Esta variedad temática tiene que ver con el concepto ilustrado de historia civil, donde no solo los reyes y sus hechos son protagonistas sino el pueblo en general.

Por esta razón la obra de Sánchez se ha encuadrado dentro del género memorialístico justificativo (se trata de una crónica), pues es algo más que un informe a sus superiores, caracterizada por un marcado carácter autobiográfico, aunque el autor intente evitarlo (no deja de recordar esto a los Commentarii de César), un evidente espíritu crítico y un sólido manejo de las fuentes propias de los medios jesuíticos ${ }^{12}$, si bien parece que algunas de las referencias que maneja las toma de forma indirecta, especialmente de Benito J. Feijoo.

Prefiere asimismo la explicación científica, avalada por la experiencia, frente a la especulación y el criterio de autoridad, en línea con el pensamiento crítico propio de la ilustración, algo que se nota desde el comienzo en su juicio sobre los mitos y tradiciones que circularon sobre el origen de las islas y sus primeros pobladores ${ }^{13}$. En fin, como síntesis de la concepción historiográfica que define la Semi-Historia sirven las siguientes palabras de F. Fajardo:

La postura de Mathías Sánchez se corresponde con la del pensamiento ilustrado, o protoilustrado, del segundo cuarto del siglo XVIII: preferencia por los modernos, frente a los antiguos; por la experiencia y la razón, contra la autoridad y la tradición; un cierto elitismo, frente a la opinión del vulgo; escepticismo crítico; rechazo del providencialismo. Por sus lecturas, sus tesis y sus relaciones personales, Sánchez puede ser situado intelectualmente en el seno del sector reformista de la Compañía de Jesús, con admiración por el método experimental y una cierta apertura hacia la crítica historiográfica ${ }^{14}$.

que los superiores de la Compañía tenían entonces una imagen distorsionada de las Islas, consideradas todavía como bárbaras, hasta el punto de que cuando regresaba algún jesuita a tierras peninsulares le advertían que no podía rozarse con hombre de prendas quien había estado mucho tiempo en Canarias.

${ }^{12}$ Cf. Sánchez, 2008: 19-23. Además F. Fajardo señala: «La narración es de carácter lineal, en orden cronológicamente progresivo; aunque a veces se vuelve para relatar algo que se ha dejado atrás, o se adelantan en la primera acontecimientos de la segunda parte, en la medida en que al tratarlos se remite a vivencias personales» (cf. Sánchez, 2008: 21-22). Entre estas fuentes estaban textos de procedencia diversa. Desde las monografías de Núnez de la Peña, Pérez del Cristo, Fray Alonso de Espinosa, Cairasco de Figueroa a autores como Mariana, Nebrija, Marineo Sículo, la obra Le Canarien, historiadores de la Compañía, historiadores de Indias y muchas otras.

${ }^{13}$ Sin embargo, según Fajardo (cf. Sánchez, 2008: 30) en otras ocasiones admite las conjeturas siempre que estén bien fundadas y lo verosímil cuando no hay pruebas y lo apoye una piadosa tradición. Es la línea que siguen otros historiadores como Ferraras, Feijoo o Flórez, una actitud que se ha calificado de "híbrida» y oportunista, que dejaba a salvo determinados mitos político-religiosos de acuerdo con las premisas políticas.

${ }^{14}$ Sánchez, 2008: 35-36. 
Tales singularidades en consonancia con el momento en que se escribió esta obra no son obstáculo para que se encuentren todavía en ella elementos que tienen que ver con una concepción teórica de la historia relacionada con los historiadores clásicos, especialmente cuando el jesuita declara los principios que han guiado su trabajo y alude expresamente a alguno de ellos.

En efecto, dos son las partes en las que este autor ofrece una descripción del propósito y modelos que ha seguido, desiguales en dimensión y argumentos. Así mientras en el «Prologo» refiere muchos pormenores sobre las condiciones y características que entiende debe tener una obra de esta clase, con referencias precisas a determinados autores clásicos, en la "Conclusion» refuerza su concepción de la historia con mención a autores sagrados ${ }^{15}$. Y esta es la primera cuestión a tratar.

El concepto que este jesuita tiene de la historia y de las cualidades que debe tener este género aparece en el «Prologo». Aquí sirviéndose del tópico de la falsa modestia, fórmula como se sabe con la que cualquier autor intenta atraerse la atención y la benevolencia de sus posibles lectores (no se olvide que ello quizás se deba al afán de justificar el título dado a esta obra, Semi-Historia ${ }^{16}$ ) declara que el objetivo fundamental de su escrito (en general, del relato histórico) es atenerse a la verdad, a pesar de que autores como Plutarco en su momento hubieran considerado esto imposible:

No sè, si es Historia esta, que presento a tus ojos, lector raro; ni pienso haia muchos que la lean. Solo sè, que es verdad quanto refiero. Esa suele darse por la primera propiedad de la Historia, y aun por su alma unica. Pero añaden los Criticos tantos otros alifafes a la razon de Historia, que se acobarda esta mia de aspirar a un titulo

${ }^{15}$ De paso refiere: «El fin de la Historia es instruir del genio de los hombres, $\mathrm{p}^{\mathrm{a}}$ aprovechar a unos con lo sucedido a otros. Avras notado en esta una continua oposicion de dictamenes. Siendo prudente no lo avras extrañado sabiendo por la Historia Sagrada lo opuesto que fueron en punto de ceremonias Judaicas y su obligacion los Principes de la Iglesia, y por la Eclesiastica los devates de un S. Cipriano con Cornelio, de un $S^{\mathrm{n}}$ Agustin con S. Jeronimo; y otras. Somos hombres: no es de estrañar, q humanos juicios se opongan» (Sánchez, 2008: 515). Esta mención de autores paganos y cristianos quizás se deba a la postura de compromiso que la Compañía de Jesús asumió, como dice L. Gil (1981: 537), «entre aquellos que, por dárselas de tener la "cristiandad toda en el pecho", condenaban la literatura gentil en bloque, y los humanistas». Una postura que ejemplifica en la figura de Antonio de Velasco, uno de los personajes de El scholástico, «quien estimaba que debía remitirse "a la prudençia del buen maestro" el alternar en la escuela la lectura de los autores paganos con la de los Padres de la Iglesia».

${ }^{16}$ Cf. Curtius, 1984: I, 127-131. Los fines que se persiguen con ello son varios: demostrar la debilidad del orador o del escritor, exponer que el tema está por encima de las fuerzas temiendo la crítica de los doctos, la incapacidad en general para realizar una tarea, el uso de un lenguaje grosero e inculto, etc. En el caso de nuestro jesuita este tópico se encuentra cuando refiere su desconocimiento de si lo que ha hecho está dentro de los cánones que la historia exige, y al final del «Prologo» cuando hace mención a la rudeza de su Minerva para realizar obras de asunto más prolijo (cf. Sánchez, 2008: 79), algo que la brevedad de la vida impide hacer, recurriendo para ello al conocido adagio de Horacio que aparece en Odas, 1, 4, 15. 
mas misterioso, y Magnifico. Puedes llamarla sencilla Narracion, o Semihistoria. Plutarco en la vida de Pericles tiene por imposible discernir el verdadero de el falso por medio de la Historia ${ }^{17}$.

El medio más oportuno para lograr este fin es que la obra histórica se escriba en vida de los individuos o en el momento en que los hechos se narran o, en su caso, pocos siglos después, circunstancia en la que él se encuentra, pues como dice:

si lo $1^{\mathrm{o}}$, impiden el conocim $^{\text {to }}$, y mas la publicacion de la verdad, el òdio, la invidia, la lisonja, u otras pasiones. Si lo $2^{\circ}$, el tiempo mismo gasta, o desfigura los fundam ${ }^{\text {tos }}$ de la verdad. Sin embargo, yo no desistiré de mi intento; porq logro las circunstancias convenientes $\mathrm{p}^{\mathrm{a}}$ decir la verdad ${ }^{18}$.

Reconoce otra vez, todavía dentro del tópico de la falsa modestia, que esta «Relacion» no le va a conceder el logro de que se le considere historiador, profesión difícil y que a duras penas daba para comer ${ }^{19}$. Indica luego que el carácter privado que tiene esta Semi-Historia, pues no fue escrita para que se publicara, hace que el estilo no se tuviera muy en cuenta y que su lenguaje no sea excesivamente culto pidiendo excusas por ello y paciencia a "q" se tomase el trabaxo de leer este borron» ${ }^{20}$.

En este sentido es Flavio Josefo a quien toma como modelo de lo que debe hacer, prefiriendo atender a la realidad que a otras cuestiones ajenas, propias del estilo. Acepta así realizar una historia sobre hechos no conocidos con la finalidad clara de transmitir a los que vengan después los sucesos de esa época, critica la labor de algunos historiadores griegos preocupados más del estilo y concede su beneplácito a aquellos historiadores que escribieron sobre una época coetánea y de la que, además, fueron contemporáneos:

Estimulóme la author ${ }^{\mathrm{d}}$ de Josefo, y mas su exemplo. Enim vero nova quidem, neq ante cognita, memoriae tradere, suiq temporis res commendare Posteris, laude ac testimonio dignum est. Por eso aplaude èl a los antiguos Escritores Asirios y Medos, prefiriendo su tarea a la de los Griegos; porq estos mas atendian a los accidentes de la Historia, galanura del estilo, eleccion de las phrases, cadencia de la (sic) silabas, y otros; que a la substancia de la realidad. Pero en los otros erat unicuique studium, quae vidisset facta, conscribere; quoniam et interfuisset rebus gestis, et efficaciter quod promittebat impleret; mentiriq apud scientes, inhonestum videretur. Si bien no faltaron Griegos de esa misma opinion, y veracidad. Sabese que Thucidides, Polibio y Strabon se resolvieron a viajar por aquellos Paises, donde avian acaecido los sucesos, que hacian el principal objeto de sus Historias ${ }^{21}$.

${ }^{17}$ Sánchez, 2008: 76.

${ }^{18}$ Sánchez, 2008: 76.

${ }^{19}$ Menciona así al historiador francés Jacques Auguste de Thou («Thuanus») (1553-1617) que decía que estos escribían no para conseguir fama, sino para poder comer.

${ }^{20}$ Sánchez, 2008: 76.

${ }^{21}$ Sánchez, 2008: 77-78. Como modelo reciente en este concepto de la historia, donde el historiador debe escribir aquellas cosas que ha visto alude a Traiano Bocalini. Por su parte los dos textos 
Esta idea es la que sustenta lo que se narra en la Semi-Historia, donde este jesuita se ha marcado como fin principal la búsqueda de la verdad, apoyándose en la condición fundamental que posibilita este hecho, esto es, el ser testigo cierto de cuanto escribe:

Y no vivi, como otros, de paso, y con ansias de volver presto a España; cosa ordinaria en los Visitadores. Y asi sera cosa fuerte dudar de mi verdad; pues a un hombre de profesion Religioso, que no tiene venal la pluma, q nada espera por su Escrito, finalm ${ }^{\text {te }}$ a $\mathrm{q}^{\mathrm{n}}$ jamàs han hallado Reo contra la Santa Veracidad, y que sobre todo eso se excusa con el ego gestis interfui, no se le puede negar una fe humana, sin ofender al candor mismo. Fuera de que puedo entrar por los ojos a qualquiera muchos papeles, cartas, y otros instrum ${ }^{\text {tos }}$ originales, en que va fundada mi asercion. Ademas de que (si reflexionan bien), atestiguaran quanto digo los Sugetos, q conmigo han vivido en Canarias, por poco q reflexionen ${ }^{22}$.

Precisa que no trata solo los asuntos grandes, sino también acontecimientos pequeños («alguien quisiera, para leer con gusto este Escrito, no encontrar a cada paso menudencias indignas de una Historia ${ }^{23}$ ) y recomienda a aquellos que buscan noticias de otra índole que lean «las Historias de un Alexandro, de un Kauli Kan, o de un Cortès; maior q ambos, y q todos los otros Heroes de Marte» ${ }^{24}$. Su obra también está exenta de relatos prodigiosos, introduce hechos que no son de gran edificación y se aleja de la loa y el panegírico (algo ajeno a lo que sería una historia).

De nuevo se sirve de la autoridad de Josefo para justificar el empleo en el texto de «exclamaciones y lamentos» (entiéndase alabanzas y críticas), aunque asume la culpa de que estos elementos aparezcan juntos:

Mezclo tal vez exclamaciones y lamentos; pero dire en mi disculpa con el citado Josefo res tribuatur Historiae, lamenta vero scriptori. Y añadire con el mismo en un sentido singular: neque etiam miserias meas celaverim, cum scientibus eas relaturus $\operatorname{sim}^{25}$.

Al final del «Prologo» se sirve de una cita de Terencio (Ad. 386-88) para justificar la introducción en el relato de predicciones futuras, las que solo aparecen cuando están fundamentadas.

de Josefo aparecen seguidos en el «Proemio» (I, 14-15), aunque Matías Sánchez los cita en orden inverso. Pero también se alude en esta cita a I, 13 donde se critica, como indica J. Ma Nieto (cf. Josefo, 1997: 75), a algunos historiadores y escritores griegos que han tratado de los judíos sin consultar los libros sagrados, y que refiere Josefo en Contra Apión I, 161-218. Son Pitágoras de Samos, Teofrasto, Heródoto, Clearco, Hecateo de Abdera, Agatárquides, Teófilo, Teódoto, Mnáseas, Aristófanes, Hermógenes, Evémero, Conón y Zopinión.

${ }^{22}$ Sánchez, 2008: 78.

${ }^{23}$ Sánchez, 2008: 78.

${ }^{24}$ Sánchez, 2008: 78.

${ }^{25}$ Sánchez, 2008: 79. 
Visto lo anterior, lo primero que cabe es referir el concepto que Matías Sánchez tiene de la historia, que por las fuentes que nombra vincula al Mundo Clásico.

Las cualidades que definen su obra y que, por ende, son esenciales en este género pueden sintetizarse en los tres puntos siguientes:

1a) Máxima que debe guiar una obra histórica: la veracidad.

$\left.2^{a}\right)$ Finalidad de toda obra histórica: instruir.

$\left.3^{a}\right)$ Momento en que debiera realizarse: cercano a los hechos que se narran, mejor

si el que escribe la historia es testigo presencial de esos hechos.

Por su parte las referencias y citas que hace este jesuita permiten que centremos el análisis en dos historiadores: Plutarco y, sobre todo, Flavio Josefo (considérese que Tucídides, Polibio y Estrabón son mencionados de pasada, aunque es lógico pensar por lo que dice que no le eran ajenos ${ }^{26}$.

De Plutarco sólo hay una mención, que pertenece a la Vida de Pericles ${ }^{27}$, donde este autor sostiene la dificultad que tiene la Historia para descubrir la verdad, pues los que viven en épocas posteriores en el tiempo no saben a ciencia cierta si los hechos que se narran son correctos, algo que también sucede cuando se mencionan acontecimientos actuales, ya que estos pueden corromper y desfigurar la verdad por efecto de la envidia, la lisonja o la adulación. Estas reflexiones, que se encuentran en Pericles, XIII, $16^{28}$, las hace contra los que se dedican a divulgar infamias, entre quienes destaca al mismo Estesímbroto de Tasos, comentador de Homero y autor de un panfleto político donde atacaba el imperialismo ateniense, quien se atrevió a referir una blasfemia contra la mujer del hijo de Pericles.

Es interesante observar que la mención y reflexión que realiza Sánchez del texto de Plutarco se encuentra también en Feijoo, con quien, como vimos, este jesuita tenía contacto epistolar. Ciertamente, Benito Jerónimo Feijoo en el «Discurso octavo» del

${ }^{26}$ Téngase en cuenta que estos tres autores son citados como ejemplo de la tercera característica que debe tener una obra histórica, esto es, ser testigo directo de los hechos que se narran. Pero además cabe indicar que alguno de estos historiadores tenía una concepción de la historia similar a la que refiere el jesuita granadino. Recordemos que Tucídides reforzó el criterio ya expuesto por Heródoto de preferir una historia contemporánea, o casi contemporánea, en la que tuviera más importancia el testimonio oral que el escrito, aunque es de notar que ambos historiadores influyeron en el hecho de que los griegos no aceptaran como historia la simple narración de relatos locales. Polibio considera la historia como verdadera investigación, a la que dota de un juicio crítico en el estudio de las fuentes, con la finalidad clara de instruir. Por su parte, Estrabón es el principal transmisor de la etnografía antigua de quien se heredó la idea de geografía histórica, elemento que aparece como se dijo (cf. supra nota 1) en el texto de Sánchez. Más detalles en Momigliano, 1984.

${ }^{27}$ Cf. García López, 2008.

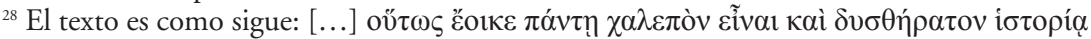

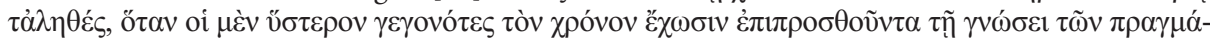

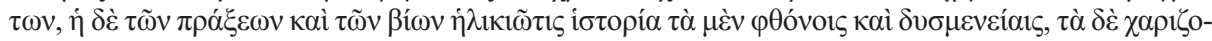

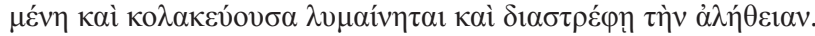


Tomo IV de su Teatro crítico universal, titulado «Reflexiones sobre la Historia», donde traduce el capítulo VI del libro primero del Tratado de la Opinión, en su primera edición, del Marqués de San Aubin refiere:

Es una reflexión muy juiciosa de Plutarco en la Vida de Pericles, que es muy difícil ó aún imposible de discernir lo verdadero de lo falso por medio de la Historia; porque si esto se escribió muchos siglos después de los sucesos, tiene contra sí la antigüedad que le impide el conocimiento de ellos; y si se escribió viviendo los sujetos de quienes trata, el odio, la envidia, ó la adulación es de creer movieron al Escritor a corromper y desfigurar lo verdadero ${ }^{29}$.

Puede verse que si el comienzo es igual en ambos autores (Sánchez había leído seguramente este texto del benedictino) luego la reflexión del jesuita se atiene más al texto de Plutarco (no precisa si lo traduce directamente del texto griego, o si lo toma de una traducción al latín o al castellano ${ }^{30}$ ) diferenciando lo que dice este en dos partes, aunque en orden inverso.

$\mathrm{Si}$ en este caso, por tanto, no debiera descartarse la existencia de esa fuente intermedia, algo totalmente diferente ocurre con los textos que cita de Flavio Josefo. Es claro que el jesuita granadino leyó su obra (se trata en este caso de La guerra de los judíos) en una versión latina ${ }^{31}$, la que acepta, como vimos, por su autoridad y su ejemplo, muestra evidente de uno de los principios manejados por la escolástica donde la ciencia se adquiría en el estudio de determinados autores sobre los que aquella se asentaba. Por el uso que hace de este autor Sánchez conocía bien este texto. Todas las citas pertenecen al "Proemio» y se sirve de ellas para aclarar los criterios que guían la redacción de la Semi-Historia y de los que no se intentará apartar.

${ }^{29}$ Consulta en línea: 10/09/2020: URL: http://www.filosofia.org/bjf/bjft408.htm. La cita pertenece al Teatro crítico universal, aparece en la edición de Madrid 1775 (por D. Blas Morán, a costa de la Real Compañía de Impresores y Libreros), tomo cuarto (nueva impresión, en la cual van puestas las adiciones del Suplemento en sus lugares), p. 221.

${ }^{30}$ Esta afirmación creo que no es gratuita teniendo en cuenta que las citas que hace de los textos de otros autores clásicos (incluido los griegos) aparecen siempre en latín. En concreto en el Fondo Antiguo de la Biblioteca de la Universidad de La Laguna, donde fueron a parar tras la desamortización y luego de muchas vicisitudes los libros que pertenecían a las órdenes religiosas, existen dos traducciones del griego al latín, una fechada en 1548 en Lyon, que lleva en la portada tachado: «Del Colegio de la Compañia de Jesús de Alcalá»; y otra de 1573 publicada en Basilea, realizada por Hermannus Crusserius, que procede de la librería del Convento de Santo Domingo de La Laguna. Es sabido que las Vidas paralelas de Plutarco tuvieron una difusión enorme a través de las traducciones que se realizaron de la misma, comenzando con la de Juan Fernández de Heredia, publicada entre 1384 y 1389, realizada a partir de la traducción que Guillermo Talodique hiciera del texto de Plutarco al griego bizantino. Cf. para más datos Lasso, 1962.

${ }^{31}$ Según recuerda J. Ma Nieto (cf. Josefo, 1997: 44) la obra de Flavio Josefo se editó por primera vez en 1470 en Augsburgo por J. Schüssler («Rufino Aquileiense interprete») si bien las ediciones posteriores como la de Basilea en 1524 son mejor consideradas. 
En efecto, en este «Proemio»-como sugiere J. Ma . Nieto, no pocas veces sigue el discurso con el que Tucídides comienza su Historia ${ }^{32}$ - Josefo ofrece claras referencias de manera casi continua sobre los criterios que le han llevado a realizar esta obra y en general los elementos que debe contener una obra de historia.

Subraya al principio lo expresado anteriormente por Plutarco al censurar a los que narran acontecimientos que desconocen por no ser testigos de los mismos, siguiendo solo lo que han oído o le han contado, crítica que extiende además a los que elogian y vituperan determinadas situaciones y hechos actuando simplemente por adulación y odio.

Pero fundamentalmente se ocupa de señalar, de forma repetida, la característica y la finalidad que debe tener toda obra histórica, que son conseguir la exactitud (así en I, 2, 6 y 9) y atenerse a la verdad (I, 6, 7, 11 y 16). Sin embargo, pese a ello, Josefo no se ve libre de críticas pues en su obra también parece que hace uso de exageraciones y tergiversaciones (cf. Esperança Rocha, 2012).

La presencia de un autor como Flavio Josefo, tomado en este caso como modelo teórico, en una obra alejada en el tiempo debe tener una explicación. La más plausible y la que más aceptación ha tenido es la que justifica la pervivencia de este autor por el eco que tuvo en ambientes cristianos. Como señala J. Ma . Nieto «en efecto, es, sin ningún tipo de dudas, el cristianismo el que más ha leído, interpretado y utilizado a Flavio Josefo» (Josefo, 1997: 40). También la recepción de este autor estudiada en parte por H. Schreckenberg (1972) para la época antigua y medieval muestra una influencia mínima en los historiadores romanos, pero grande en los autores cristianos.

Las bibliotecas de los jesuitas no fueron ajenas a su obra ${ }^{33}$ como tampoco la de otras instituciones o universidades ${ }^{34}$, y ello porque el estudio de la lengua griega era indiscutible. Así señala L. Gil (1995: 280) que

la enseñanza de la lengua griega, pese a las prevenciones iniciales de San Ignacio de Loyola, fue incluida en las Constituciones de la Compañía de 1558. Y así, figuró tanto en las redacciones provisionales de la Ratio atque institutio studiorum de 1586 y 1591 sometidas a consulta, como en su versión definitiva de 1599.

Por lo que aquí se trata, es difícil saber, al no tener noticias concretas de ello, dónde puedo haber consultado Matías Sánchez el texto de Josefo (al igual que

${ }^{32}$ Apunta además J. Ma Nieto (cf. Josefo, 1997: 38) que, aparte de Tucídides, Josefo se inspira en Heródoto, Jenofonte y Polibio. Con este último comparte el hecho de que los dos escribieron durante su exilio en Roma, admiraron la grandeza de Roma y su relación con sus pueblos respectivos.

${ }^{33}$ Cf. como ejemplo de ello, Valenzuela, 2016. En este caso el texto de Josefo corresponde a Antiquitates, y la autora se apoya en una afirmación de M. Hadas-Lebel para justificar que el mayor número de obras de este autor se debe a la aceptación que tuvo entre los cristianos.

${ }^{34}$ Como muestra de ello entre las ediciones grecolatinas del siglo XVI que se encuentran en la Universidad de Santiago de Compostela, la Guerra Judía de Josefo tiene más ejemplares que Tucídides, incluso a pesar de ser un autor que se encontraba dentro de los índices inquisitoriales porque podía propiciar el orgullo racial de los judíos (cf. Amado-Pereiro, 1987: 72-73). 
el de Plutarco). Aunque como se dijo antes la redacción definitiva de la Semi-Historia la realizó cuando ya había sido trasladado a la Península (concretamente en Málaga) ${ }^{35}$, quizás tuvo la oportunidad de consultar alguno de estos autores cuando se encontraba en las Islas ${ }^{36}$. Los tres Colegios que tenía la Compañía en Canarias contaban con su propia biblioteca, fundamental para la formación de los padres y para la enseñanza externa que impartían ${ }^{37}$. En concreto, de la biblioteca del colegio de La Orotava tenemos los datos recientes que aporta J. Hernández Bravo (2015: 219-234) ${ }^{38}$, aunque no aparecen ninguno de estos autores entre los volúmenes registrados.

${ }^{35}$ En efecto como indica F. Fajardo (cf. Sánchez, 1997: 11): «En el Colegio de Málaga, donde estuvo entre 1736 y 1750, terminó su Semi-Historia. Según él mismo nos dirá, acabo extraviando más tarde el texto elaborado, por lo que debió rehacerlo a partir del primer borrador, completando su "traslado" el 14 de febrero de 1754. Varios pasajes hacen patente que se actualiza una versión anterior. La necesidad de volver sobre el manuscrito inicial le dio la ocasión de hacer algunos añadidos e introducir algunas precisiones y correcciones, sobre todo de carácter cronológico».

${ }^{36}$ Ejemplares de estos autores se encuentran actualmente en los fondos de las bibliotecas canarias. Nada menos que cinco ediciones de la obra de Josefo, en latín y en griego, alberga el Fondo antiguo de la Biblioteca de la Universidad de La Laguna. Son por orden cronológico (añado su procedencia cuando se indica): Lugduni, apud S. Gryphium, 1546 (Exlibris ms.: «Francisco de Medina»); Francofordi ad Moenum, impensis S. Feyerabendii, 1588; Coloniae, apud I. Gymnicum, 1593 (procede de la Librería de Santo Domingo de La Laguna); [s.l.], sumptibus S. Crispini, 1611; Genevae, apud P. Aubertum, 1635 (Exlibris ms.: «D. Porlier»). Además hay una traducción al castellano de la Guerra de los judíos hecha por Alonso de Palencia y corregida por Erasmo, Anvers, 1551 (Exlibris ms.: «Porlier»), y una traducción flamenca de 1626. Curiosamente en la biblioteca Municipal de La Orotava encontramos una traducción al inglés de las obras de Josefo «according to Havercamp's accurate edition» realizada por William Whiston (Dublín, 1741), procedente del fondo antiguo de Lugo y Massieu. Para Plutarco cf. n. 29 del presente trabajo.

${ }^{37}$ De las tres bibliotecas con que contaba la Compañía en las Islas, una por cada Colegio, ofrece datos Escribano Garrido (1987: 507-510) con noticias desiguales. De la que estaba en el Colegio de La Laguna solo se sabe que tenía 300 volúmenes y de la que se encontraba en el Colegio de La Orotava, donde Matías Sánchez pasó más tiempo, se hizo un inventario a raíz de la expulsión, con lagunas en la identificación de las obras, y constaba de 746 volúmenes. Es de la biblioteca del Colegio de Las Palmas de la que ofrece más detalles. Tenía un total de 1.237 volúmenes de los que se conocen no solo las materias que trataban sino el lugar de edición de las obras. A falta de datos sobre las otras bibliotecas, Escribano toma como ejemplo la de Las Palmas para hablar de la organización y las partes que contenían, aparte de ofrecer títulos y autores. A las secciones de jurisprudencia y cánones, obras teológicas y ciencias se une la parte dedicada a la pedagogía, la gramática, los autores clásicos y la literatura castellana. No menciona ningún autor clásico en concreto, solo que el montante de libros de esta sección ascendía a 32 volúmenes.

${ }^{38}$ Refiere Hernández Bravo (2015: 221) la dificultad de «seguirle la pista» a los 750 volúmenes de esta biblioteca (véase la diferencia con los datos que aporta Escribano en la nota anterior), muchos de los cuales han pasado a diversos fondos antiguos y otros han desaparecido. Tras la expulsión de la Compañía, Carlos III dicta dos decretos, uno para que se hiciera inventario de los libros y papeles de los colegios y otro sobre el destino que debía dárseles. Los libros procedentes de los Colegios debían conformar sendas bibliotecas en cada diócesis según Real Cédula de 17 de febrero de 1771. Ello ha permitido saber el destino de algunos de estos volúmenes y dónde se encontraban. La mayor cantidad de libros aparece en la habitación de los visitadores, al no estar ocupada de continuo. En la del rector de hallaron 151 libros en 277 volúmenes, y en la del maestro de Gramática 131 títulos en 242 volúmenes. 
Como se ve todavía hay incógnitas que resolver y otras carencias de las que solo se pueden dar hipótesis al no tener información concreta (incluso este «Prologo» debió hacerse posteriormente tras la redacción definitiva del texto como era habitual). No obstante lo que resulta evidente es que la cultura clásica (autores, géneros literarios, conceptos teóricos) permance vigente en el tiempo y en ella se fundamentaba todavía la formación y el trabajo intelectual, lo que vendría a explicar su pervivencia en obras de contenido tan diverso (tanto en latín como en vernáculo) como la que aquí se trata.

\section{REFERENCIAS BIBLIOGRÁFICAS}

Amado Blanco, T. - Pereiro Pardo, A. (1987): «Las ediciones greco-latinas del s. XVI en la biblioteca de la Universidad de Santiago", EClás 91: 65-74.

CurTius, E. R. (1984): Literatura europea y Edad Media latina, F.C.E., México.

EsCribano Garrido, J. (1987): Los jesuitas y Canarias (1566-1767), Facultad de Teología, Granada.

ESPERANÇA RochA, I. (2012): «Josefo: entre la historia y la ficción», en G. N. HAMAMÉ - M. a C. SCHAMUN (eds.), Actas del VI Coloquio Internacional AГQN. Competencia y cooperación de la Antigua Grecia a la actualidad. Homenaje a Ana M. ${ }^{a}$ González de Tobia, Universidad Nacional de La Plata, Centro de Estudios Helénicos, La Plata, pp. 355-365.

García López, J. (2008): «Estructura formal y elementos religiosos en las Vidas de Plutarco: Pericles», Myrtia 23: 87-99.

GIL, L. (1981): Panorama social del humanismo español (1500-1800), Alhambra, Madrid.

GIL, L. (1995): «El griego en la educación de las élites españolas del siglo XVIII», Bulletin Hispanique 97.1: 279-298.

JosEFO, F. (1997): La Guerra de los judíos. Libros I-III, introducción, traducción y notas de J. Ma NIETO IBÁÑEZ, Gredos, Madrid.

Lasso de la Vega, J. S. (1962): «Traducciones españolas de las Vidas de Plutarco», EClas 6: 451-514.

MARTíNEZ, M. (2007): «La tradición clásica en la historiografía canaria del siglo XIX: Gregorio Chil y Naranjo», El Museo Canario 62: 307-352.

Momigliano, A. (1983): «Historia y biografía», en M. I. Finley (ed.), El legado de Grecia. Una nueva valoración, trad. esp. de A. Prometeo Moya, Crítica, Barcelona, pp. 166-195.

Momigliano, A. (1984): Historiografía griega, Crítica, Barcelona.

Rodríguez Bravo, J. (2015): Los Jesuitas y las artes en La Orotava, Le Canarien ediciones, Santa Cruz de Tenerife.

SÁnchez, M. (2008): Semi-Historia de las Fundaciones, Residencias, o Colegios que tiene la Compañia de Jesus en las Islas Canarias, transcripción, estudio introductorio y notas de F. FAJARDO SPíNOLA, Instituto de Estudios Canarios, La Laguna.

SChreckenderg, H. (1972): Die Flavius-Josephus Tradition in Antike und Mittelalter, E. J. Brill, Leiden.

VAlenZuela Matus, C. (2016): «Griegos y romanos en un Colegio jesuita del fin del mundo. Renacimiento y libros clásicos en el inventario de la biblioteca del Colegio Máximo de San Miguel», Revista Historia del Orbis terrarum 17: 73-93. 
